ISSN: $1130-3743$

\title{
EL RECONOCIMIENTO Y LA ACREDITACIÓN DE LA EXPERIENCIA ${ }^{1}$
}

\section{Recognition and accreditation of experience}

\section{Validation et accréditation de l'expérience}

\author{
Óscar Medina Fernández* y Florentino Sanz Fernández*** \\ * Universidad de Las Palmas de Gran Canaria. Facultad de Formación del \\ Profesorado. Departamento de Educación. C/ Juana de Arco, 1. 35003 Las Palmas \\ de Gran Canaria. Correo-e: omedina@dedu.ulpgc.es \\ * Universidad Nacional de Educación a Distancia. Facultad de Educación. \\ Departamento de Historia de la Educación y Educación Comparada. Edificio \\ de Humanidades. Paseo Senda del Rey, 7. Madrid
}

Fecha de recepción: marzo de 2009

Fecha de aceptación definitiva: julio de 2009

Biblid [(1130-3743) 21, 2, 2009, 165-193]

\section{RESUMEN}

Según los datos de la Encuesta de Población Activa del 2006, el 44,3\% de la población ocupada española carece de formación relacionada con el trabajo. Como sucede prácticamente en todos los países desarrollados, se trata de unos trabajadores que no han podido estudiar en su momento y se han puesto a trabajar desde muy jóvenes y es precisamente en el puesto de trabajo donde han aprendido lo que saben

1. Este artículo pertenece al proyecto UNI2005/23 titulado Sistemas de Acreditación, financiado por la Universidad de Las Palmas de Gran Canaria. Los componentes del grupo de investigación, al que pertenecía nuestro entrañable compañero y amigo Florentino Sanz Fernández, quieren dejar constancia de su dedicación en este trabajo de investigación y de sus extraordinarias aportaciones. 
y ponen al servicio de la producción. Dicho de otra manera, son trabajadores que han adquirido las competencias propias de una titulación profesional, pero no tienen el título correspondiente. Los sistemas de acreditación de la experiencia tratan de hacer justicia con estos trabajadores, reconociendo y certificando que mediante sistemas no formales o informales de educación han podido adquirir las competencias propias de una titulación.

Presentamos en este artículo parte de los resultados de un trabajo de investigación sobre Sistemas de Acreditación: en primer lugar abordamos el concepto de competencia y el de evaluación de la competencia; a continuación hacemos una reseña sobre la metodología, los documentos o protocolos que se emplean en los sistemas de acreditación y las fases a seguir; finalmente entramos en el modo en que estos sistemas de acreditación de la experiencia se están planteando a nivel internacional y en España.

Palabras clave: competencias, competencias laborales, acreditación, Sistemas de Acreditación, valoración de adquisiciones, aprendizaje a lo largo de la vida, Educación Permanente, Educación de Adultos, Formación Profesional.

\section{SUMMARY}

According to a 2006 survey of the working population, $44,3 \%$ of employees don't have the proper qualifications for their employment. As it happens in all developed countries, these workers didn't have the opportunity to study when they were young and started to work at a very young age and is at their work place where they have learnt all they know. In a way, they are workers that have obtained their professional skills at their work place but lack the proper qualifications. The accreditation system tries to do justice with these workers by recognizing and certifying that they have obtained their professional skills qualifications by Non Formal and Informal means of Education.

In this paper we show part of the results of a research about the Accreditation System: firstly we discuss the concept of competence and its evaluation; secondly we talk about the methodology, the protocols used in the accreditation system and the various stages to follow; finally we look at the way these accreditation systems are being formulated at international levels and in Spain.

Key words: competences, work competences, accreditation, Methods of Accreditation, recognition of competences, evaluation of acquired learning, lifelong learning, Permanent Education, Adult Education, Vocational Training.

\section{SOMMAIRE}

Selon les données de l'Enquête sur la Population Active de 2006, le 44,3\% de la population occupée espagnole n'a pas de formation en rapport avec son travail. Comme au reste des pays développés, il s'agit de travailleurs qui n'ont pas étudié dans leur jeunesse. Ils ont commencé à travailler très jeunes, et c'est dans leur travail qu'ils ont appris ce qu'ils savent et qu'ils mettent en pratique au service de la production. Autrement dit, ce sont de travailleurs qui ont acquis les compétences propres 
d'un titre professionnel, mais qui n'ont pas ce titre. Les systèmes d'accréditation de l'expérience cherchent de faire justice à ces travailleurs, tout en reconnaissant et certifiant qu'ils ont pu acquérir les compétences propres d'un titre professionnel à travers de systèmes formels ou non formels d'éducation.

Nous présentons dans cet article une partie des résultats d'un travail de recherche à propos des Systèmes d'Accréditation: premièrement nous y traitons le concept de compétence et celui d'évaluation de la compétence; après nous parlons de la méthodologie, les documents qu'on emploie aux systèmes d'accréditation et les phases à suivre; finalement nous exposons la manière de traiter ces systèmes d'accréditation de l'expérience à niveau international et en Espagne.

Mots clés: compétences, compétences en travail, accréditation, Systèmes d'Accréditation, validation des acquis, apprentissage tout au long de la vie, éducation permanente, éducation des adultes, formation professionnelle.

\section{INTRODUCCIÓN}

El reconocimiento y la acreditación de la experiencia es una práctica educativa que se ha extendido prácticamente en todos los países desarrollados, aunque con una antigüedad diferente: en algunos países, como Estados Unidos, desde hace casi un siglo; y en otros, como España, no cuentan más de una década. En esencia, estamos hablando de un proceso de evaluación mediante el cual una persona, con una determinada experiencia laboral y social, puede conseguir una titulación oficial, a pesar de no haber recibido las correspondientes enseñanzas en un centro de formación.

En nuestro país tenemos un importante sector de la población en esta situación. Según los datos de la Encuesta de Población Activa, el 44,3\% de la población ocupada carecía de formación relacionada con el trabajo en el año 2006 (INE, 2007). Se trata de unos trabajadores que no han podido estudiar en su momento y se han puesto a trabajar desde muy jóvenes, siendo precisamente en el puesto de trabajo donde han aprendido lo que saben y ponen al servicio de la producción. Ello sólo ha sido posible porque en la empresa se han interesado por aprender y mejorar su desempeño, atentos siempre a la calidad, preguntando lo que desconocían o no sabían hacer, reflexionando sobre su propio quehacer, estudiando de forma autónoma y acudiendo a los cursos de formación del sindicato, de la patronal del sector o de la propia empresa. Para muchos trabajadores éste ha sido el camino que les ha conducido a ser empleados eficientes, y, en no pocos casos, llegar a desempeñar la función de jefe de grupo, responsable de algún departamento e incluso miembro de la dirección. Es evidente que si una empresa mantiene a estos trabajadores será porque han dado muestras de su profesionalidad; más aún si la empresa, por ejemplo, nombra a uno de estos empleados Jefe de Cocina, Director de Contabilidad, Jefe de Compras, Jefe de Taller o Gerente, será porque para el consejo de administración existen evidencias suficientes sobre la competencia de 
estos trabajadores y sobre su capacidad de liderazgo para conducir un departamento, una sección o la propia empresa.

Así pues, hablamos de unos trabajadores que no han sido formados mediante la formación inicial-formal sino a través de su propia experiencia. Y es ahí, en la práctica, en la experiencia, en el lugar de trabajo, donde han adquirido las competencias (en términos de conocimientos, habilidades y actitudes) que les convierten en un profesional. Dicho de otra manera: no están titulados, pero poseen las competencias de un titulado.

Situémonos, por ejemplo, en el caso de un Jefe de Taller (rama de Fabricación Mecánica), con 25 años de experiencia, pero que no tiene ninguna titulación de carácter profesional: si a este trabajador lo evalúa un tribunal, compuesto por enseñantes de la titulación correspondiente de Formación Profesional, y comprueba que posee las mismas competencias que las que obtienen los alumnos de la titulación durante la formación, decimos que el tribunal podrá acreditar a este trabajador, lo que quiere decir que firmará un acta en la que se certifique que posee tales competencias, del mismo modo que los miembros de dicho tribunal evalúan y titulan a sus alumnos en los respectivos centros de enseñanza. A continuación, si este Jefe de Taller posee las condiciones de acceso (que según las normas vigentes en nuestro país, para las enseñanzas de Formación Profesional de grado superior es el título de Bachillerato o equivalente), se le otorgará el título de Formación Profesional de Grado Superior de Técnico Superior en Construcciones Metálicas (ésta es la denominación de las enseñanzas y del título). En caso de no poseer tales condiciones, este trabajador podrá contar con un certificado en el que se hace constancia de que posee todas o parte de las competencias del citado título.

Desde el punto de vista educativo, lo que hace el tribunal es abrir un proceso de evaluación para reconocer y certificar (eso es acreditar), en términos de enseñanza formal, las competencias que este trabajador ha podido adquirir a lo largo de su vida, no mediante la formación inicial-formal, sino mediante enseñanzas no formales (como la formación ocupacional y continua) o a través de procesos informales de educación (como la experiencia que ha adquirido a lo largo de su vida).

A estos procesos de evaluación es a lo que se le llama reconocimiento y acreditación de la experiencia, o también sistemas de acreditación de competencias, que es la expresión que se usa en buena parte de la legislación española, aunque no faltan otras expresiones como sistemas de reconocimiento, evaluación y acreditación de los aprendizajes no formales e informales. En otros países, sin embargo, se habla de balance de competencias, o de valoración de adquisiciones de la experiencia. En cualquier caso todo esto significa reconocer que una titulación oficial se puede obtener mediante los sistemas de enseñanza formales tradicionales y también mediante estos sistemas de reconocimiento y acreditación de la experiencia. Dicho de otra manera, tanto la enseñanza como la experiencia son fuente de formación para la adquisición de competencias. No en vano, en algunos documentos internacionales que hablan de este asunto (Delors et al., 1966, 158), se dice que estamos ante lo que también se denominan nuevos sistemas de titulación. 
Lo esencial de estos sistemas de reconocimiento y acreditación de la experiencia es que se trata de la intervención de profesionales de la educación en determinados procesos de evaluación de la competencia, independientemente de cómo se hayan adquirido tales competencias.

Todo el mundo reconoce que estos nuevos sistemas de titulación representan un importante reto educativo, pero no menos dificultades prácticas para llevarlos a cabo con el rigor que estas prácticas educativas merecen. En el fondo, el problema lo tenemos en el propio concepto de competencia y la dificultad que supone su evaluación.

Presentamos en este artículo parte de los resultados de un trabajo de investigación sobre Sistemas de Acreditación: en primer lugar abordamos el concepto de competencia y el de evaluación de la competencia; a continuación hacemos una reseña sobre la metodología, los documentos o protocolos que se emplean en los sistemas de acreditación y las fases a seguir; finalmente, entramos en el modo en que estos sistemas de acreditación de la experiencia se están planteando a nivel internacional y en España.

\section{El CONCEPTO DE COMPETENCIA Y SU EVALUACióN}

Dado que la acreditación de la experiencia o los sistemas de acreditación se basan en la evaluación de la competencia, es obligado que entremos en estos dos conceptos. Lo primero que hemos de decir es que estamos ante un concepto, el de competencia, que, como una mancha de aceite, se está extendiendo por todos los vericuetos de la empresa y sus planes de formación, para finalmente terminar colonizando buena parte del universo educativo. Rodríguez Moreno $(2006,51)$ habla en este sentido de la «emergencia imparable de la noción de competencia". Ello explica que en la literatura pedagógica de los últimos veinte años se hable de competencias a la hora de definir los currículos y diseñar las acciones formativas.

La importancia que está teniendo el concepto de competencia en la educación es lo que lleva a muchos autores a afirmar que estamos ante un cambio de enfoque (paradigma, dicen otros) de la educación, basada ahora en el aprendizaje, frente al enfoque tradicional, apoyado en la enseñanza (Vergara, 2003; Bajo y Maldonado, 2003 , entre otros). Insistimos en lo de cambio de enfoque o de paradigma, porque se trata de algo más que de una transformación gradual o un mero cambio de énfasis. En realidad asistimos a toda una nueva concepción del quehacer educativo, que se sitúa, ahora con más propiedad y alcance, en la órbita de la educación permanente, transformando de este modo el papel del educador, el del mismo alumnado y la propia relación educativa. Pero no sólo eso: también el concepto de competencia está cambiando los diseños educativos, el modo de conducir el proceso de enseñanza-aprendizaje, así como los sistemas de evaluación y la propia selección de instrumentos evaluadores. 


\subsection{Por qué surge el concepto de competencia}

Fundamentalmente hay dos razones que explican la emergencia del concepto de competencia en el mundo de la educación. Una de ellas tiene que ver con las transformaciones del universo del trabajo, toda vez que actualmente se tiende a pensar que la formación basada en la competencia responde mejor a las nuevas demandas del mercado laboral. Tradicionalmente el trabajador aprendía un oficio, de carpintero, por ejemplo, o de sastre, o de contable, y ejercía este trabajo a lo largo de su vida; los cambios en el desempeño de su oficio eran mínimos y todo lo que se le pedía era hacer su trabajo lo mejor posible y siempre como lo había aprendido; en eso consistía ejercer bien su oficio; su trabajo estaba claro, su tarea era precisa, sin posibles incertidumbres; todo el trabajo estaba definido de antemano.

Ahora a los trabajadores no les vale aplicar lo que saben, pueden tener un oficio bien aprendido y encontrarse con nuevas exigencias que les pueden hacer fracasar en su trabajo. El carpintero se encuentra con un nuevo tipo de madera sintética que antes no había visto y sus herramientas no le sirven; el sastre se va quedando sin clientes que acuden a los grandes centros de confección que abaratan el producto, al contable no le queda más remedio que usar los programas informáticos si quiere continuar y ser efectivo en su trabajo.

Lo que sucede es que ha cambiado el mundo del trabajo debido a las constantes transformaciones tecnológicas (nuevos productos, nuevas herramientas, informática, nuevas tecnologías de la comunicación, Internet, etc.) y también debido a los cambios sociales (nuevos hábitos de consumo, nuevos mercados, globalización, grandes centros comerciales, etc.). El nuevo tipo de trabajador que hoy se requiere no es el que sabe un oficio, o el que tiene unos conocimientos teóricos y prácticos, o el que tiene que realizar tareas específicas de un puesto de trabajo, sino el que sabe responder a las diversas eventualidades que se le van a plantear en su trabajo y además el que sabe transmitirlo a los demás.

Esto es lo que Dennery (1997) denomina "proceso de transferencia pedagógica", consistente en la capacidad de "transformar los conocimientos teóricos y prácticos en competencias clave, es decir, en saber, saber hacer y saber ser, y que se puedan poner en funcionamiento ante una situación profesional dada" (Sabán, 2000). Ésta es la idea de competencia (resolver problemas, comunicación, espíritu emprendedor, trabajo en equipo, flexibilidad, creatividad, educación permanente, responsabilidad, capacidad para resolver eventualidades, etc.) (Rial, 2000) que convierte a un trabajador en una persona capaz de responder con eficiencia a las diversas demandas que se plantean en su trabajo y en el sistema productivo. Según Grefee, la competencia se asocia al nivel más elevado de conocimientos técnicos, se concibe como una especie de desmaterialización de los empleos y su desprofesionalización en beneficio de aptitudes más abstractas y generales que pueden ser aplicables en situaciones diversas, inciertas e imprecisas (Monclús, 2000; Grefee, 1997). 
La otra razón que explica la emergencia del concepto de competencia precisamente está relacionada con el tema que nos ocupa: la acreditación de la experiencia. No podemos olvidar que cuando hablamos de acreditar la experiencia estamos suponiendo que la experiencia, al igual que la formación, es fuente de aprendizaje de competencias, se hayan adquirido éstas por vías formales, no formales o informales. Por esta razón, dice Colardyin (2002), las competencias se convierten en el mejor vehículo para evaluar cualquier aprendizaje, sea formal, no formal o informal.

Todo parece indicar, por tanto, que no es posible la aplicación de sistemas de reconocimiento y acreditación si la formación previamente no se ha diseñado en términos de competencia. En este sentido cabe señalar que en algunos países europeos, como Francia, por ejemplo, las universidades pueden solicitar la apertura de sistemas de acreditación de la experiencia, y el Ministerio sólo les pone la condición de que posean los títulos definidos en términos de competencia.

\subsection{La competencia como un constructo subyacente}

Como vemos, parece que hay acuerdo en reconocer las ventajas que tiene el concepto de competencia en el nuevo marco laboral al que estamos asistiendo. Pero no sucede lo mismo a la hora de precisar los perfiles y características del propio término. Los estudiosos de este asunto reconocen que no existe suficiente consenso en torno al concepto de competencia. Ello es debido, entre otras razones, a que, como dicen Jover et al. (2005, 62), los empresarios y los docentes se refieren a este término de forma diferente: los primeros hablan de desempeño, eficiencia y productividad; y los otros lo asocian con capacidades y conocimientos.

Pero el problema todavía es más complejo -insisten Jover et al.- en la medida en que sigue sin estar claro si la competencia se refiere a lo que se es capaz de hacer o a lo que realmente se hace (p. 67). Dicho de otra manera, si la competencia se refiere a la capacidad (poder) o a la actuación (realidad). De hecho no pocas definiciones se refieren a la competencia en términos de capacidad. Así por ejemplo, Perrenaud (2002) define la competencia como la capacidad para movilizar recursos en orden a resolver una determinada situación práctica. Spencer y Spencer (1993) se refieren a la competencia como una característica del individuo que tiene que ver con un rendimiento efectivo en una situación de trabajo.

Otros autores hablan de la competencia como conjunto de conocimientos, habilidades y actitudes que posee una persona, que le permiten la realización de una actividad. Bunk (1994) define la competencia como conjunto de conocimientos, destrezas y aptitudes cuya finalidad es la realización de actividades vinculadas a una profesión. En España, el Instituto Nacional de Empleo se refiere a las competencias como conjunto de conocimientos, habilidades y aptitudes que permiten a los profesionales desempeñar y desarrollar roles de trabajo en los niveles requeridos para el empleo. Por su parte, la Ley Orgánica 5/2002 de las Cualificaciones y de la Formación Profesional define la competencia profesional como "el conjunto 
de conocimientos y capacidades que permiten el ejercicio de la actividad profesional conforme a las exigencias de la producción y el empleo" (art. 7.3.b).

Tal diversidad se pone de manifiesto en el análisis conceptual que, a partir de la bibliografía consultada, hace la profesora Rodríguez Moreno, de la Universidad de Barcelona, distinguiendo entre varios modelos de definiciones de la competencia: modelos unidimensionales, que asocian la competencia con una determinada dimensión de la persona; modelos multidimensionales, que recogen la contribución de varios componentes del individuo; y modelos integradores, que suponen una reelaboración ecléctica y superadora de los modelos anteriores (Rodríguez Moreno, 2006, 47-84).

Esto es sólo una muestra de la falta de acuerdo en una cuestión tan importante como la definición del concepto de competencia, lo que pone de manifiesto que estamos ante un concepto complejo y multívoco. Los científicos, sobre todo los científicos sociales, suelen utilizar la expresión "constructo" para abordar conceptos complejos como el de competencia. Un constructo es, por ejemplo, la inteligencia, o la personalidad, expresiones que aluden a algo que no vemos directamente, sino que suponemos su existencia a partir de determinados efectos.

En tal sentido, hay autores que dicen que la competencia es una estructura holística de carácter cognoscitivo, un constructo subyacente (Spencer y Spencer, 1993; Gonczi, 1997), es decir, un sustantivo abstracto, intangible, teórico, que no se observa directamente sino que lo vemos a partir de determinadas conductas, relaciones o resultados. Boyatzis (1982) es otro autor que se refiere a la competencia como una característica subyacente de una persona que se compone de aptitudes y habilidades, rasgos de personalidad, actitudes y valores, conocimientos y motivos.

Tal vez la metáfora que explique mejor lo que decimos es la del iceberg del propio Boyatzis (1982), que define la competencia como una característica subyacente de la persona, al igual que la parte más grande del iceberg. Debido a una notable propiedad del agua (que en su forma sólida tiene menor densidad que en estado líquido), en un iceberg se distingue entre lo que está por encima de la línea de flotación y lo que está por debajo. La competencia vendría a ser lo que está por debajo de la línea de flotación, es lo que no vemos, pero es lo más importante del iceberg, la parte más grande, la parte profunda del individuo. Ésta es la idea de constructo: la competencia es como un constructo subyacente, no observable en sí mismo (no vemos lo que está por debajo de la línea de flotación), sino de modo indirecto a través de las realizaciones y comportamientos (que es lo que vemos porque está por encima de la línea de flotación).

Es importante lo que decimos (que la competencia subyace, no es observable en sí misma), algo que debe estar claro, tanto en los procesos de enseñanza (ya que no se enseñan competencias sino capacidades) como en los procesos de evaluación (pues tampoco se evalúan las competencias sino las capacidades). En el caso de la enseñanza, las capacidades se aprenden mediante contenidos conceptuales, procedimentales y actitudinales; y en el caso de la evaluación, las 
capacidades se evalúan mediante evidencias sobre los componentes observables de los conocimientos, los procedimientos y las actitudes.

Esta idea de la competencia como una realidad subyacente, como la parte no visible del iceberg, la que está por debajo de la línea de flotación, es lo que nos permite avanzar en esta misma dirección y preguntarnos cuáles son los componentes de la competencia, qué es realmente lo que está por debajo de la línea de flotación. La diversidad de respuesta en este caso no es menor que sobre el propio concepto de competencia. En nuestro caso, coincidiendo con otros muchos autores (Gutiérrez y Castañeda, 2001; Echeverría, 2002; entre otros), preferimos hacer una propuesta de tres componentes. Partimos del concepto general de competencia siguiente: una persona es competente si tiene la preparación o la capacidad suficiente para realizar las tareas o actividades propias de una profesión o puesto de trabajo. Por tanto, se trata de un saber hacer que es algo más que pericia, pues se supone que la persona competente no sólo hace lo que sabe (procedimientos, técnicas, etc.), sino que sabe lo que hace (sabe explicarlo y dar razón de ello) y, además, realiza la tarea de acuerdo con criterios de calidad y con una actitud permanente de mejora y superación. En suma, hablamos de una preparación o capacidad que nos indica que la persona competente ha adquirido tres importantes aprendizajes, que son los componentes o las dimensiones de la competencia:

a) Realiza las tareas propias de la profesión. Es el saber hacer, o el núcleo procedimental de la competencia. Significa que el trabajador usa los procedimientos y las técnicas de su trabajo con rigor, calidad, en contextos diferentes y de forma innovadora.

b) Conoce los conceptos implícitos en las tareas. Es el saber, núcleo cognoscitivo de la competencia. Indica que se dominan los conceptos y los fundamentos que subyacen en la realización de las tareas; lo que quiere decir que la persona competente en este caso sabe explicar lo que hace y justifica el modo en que realiza su trabajo.

c) Posee una actitud y unos valores propios de la profesión. Es el ser, estar y convivir, núcleo actitudinal de la competencia. Tiene lugar esta dimensión cuando la persona posee una actitud de rigor y calidad en relación con su desempeño profesional y con el propio grupo en el que está integrado. Se trata de un actitud positiva ante su profesión, que le conduce a conocer sus límites y a preocuparse por su formación a lo largo de su trayectoria profesional.

\subsection{La evaluación basada en la competencia}

Lo que se conoce como evaluación basada en la competencia se entiende que presenta algunas diferencias a la evaluación basada en la formación, que tradicionalmente se ha practicado en los centros del sistema educativo formal: escuelas, institutos y universidades. Ello no quiere decir, como reconocen algunos autores, 
que en el mundo de la educación no proceda hablar de evaluación de competencias (Gutiérrez y Castañeda, 2001). Independientemente de que el debate sobre tal distinción tenga base o no, lo cierto es que en los sistemas de acreditación se suele llevar a cabo este modelo de evaluación basada en la competencia, que lo que busca son evidencias que prueban que la persona es competente para ejercer una profesión de acuerdo con un determinado perfil profesional. Es decir, se trata de comprobar si se sabe (no importa dónde, cuándo ni cómo se ha aprendido, dado que el aprendizaje se ha podido vehicular a través de la formación o por medio de la experiencia), y si es capaz de llevar a la práctica lo que sabe, de acuerdo con estándares de calidad, sea en contextos conocidos, o desconocidos de antamano.

Como vemos, estamos hablando de los resultados del aprendizaje: las competencias, cuya existencia no se observa directamente, sino de modo indirecto. Insistimos en lo dicho, porque si afirmamos que las competencias no se ven, no se observan, sino que suponemos su existencia (su aprendizaje), ello querrá decir consiguientemente que, por las mismas razones, las competencias no se pueden evaluar directamente o por sí mismas, sino mediante algo que sí vemos y sí observamos. Eso que sí vemos y observamos son las evidencias que, al ser evaluadas, nos hablan de la existencia de competencias. ¿Cuáles son esas evidencias que sí podemos evaluar y que nos remiten a las competencias?

a) La práctica profesional. Son las evidencias de actuaciones y ejecuciones profesionales, que las obtiene el evaluador mediante la observación del candidato en el puesto de trabajo o, fuera del puesto de trabajo, mediante pruebas simuladas; y en ambos casos, también a través de productos o resultados del trabajo y por otros medios.

b) Las producciones orales y escritas. Éstas son otras evidencias que obtiene el evaluador, que se añaden a las anteriores. Hablamos en este caso de productos que elabora o cumplimenta el candidato (entrevistas, cuestionarios, pruebas, proyectos, trabajos escritos, etc.) en relación con su práctica profesional. También estas producciones orales y escritas pueden ser aportadas por otras personas acerca del candidato (certificados de trabajo, informe del empleador, testimonios de testigos, etc.), ampliando de este modo el conjunto de evidencias del solicitante de la acreditación.

En el fondo éstos son los dos grandes medios que se emplean en los sistemas de reconocimiento y acreditación de la competencia. Cuando un profesional, que no posee título alguno, aspira a que se le evalúe para poder titular, lo que hacen los evaluadores es analizar las evidencias sobre su desempeño profesional y sobre sus propias manifestaciones orales y escritas en relación con dicho desempeño. Tales evidencias pondrán de manifiesto que este profesional posee o no las competencias asociadas a una determinada titulación del sistema educativo.

A diferencia de lo que se hacía en la evaluación tradicional de la enseñanza, la ventaja que tiene evaluar las competencias (aunque éstas se tengan que evaluar de forma indirecta, como acabamos de decir), es que, como ya hemos 
comentado anteriormente, la competencia se convierte de este modo en el vehículo (cfr. Colardyn, 2002) para poder evaluar cualquier aprendizaje, sea formal, no formal o informal, se haya adquirido mediante la formación o mediante la experiencia. Estamos pues en el territorio de la evaluación que permite el reconocimiento de los aprendizajes fruto de la experiencia, facilitando así la acreditación.

\section{Metodología, protocolos y fases en los sistemas de ACReditación de la eXPeriencia}

A la hora de definir la metodología general y los pasos a seguir en los sistemas de acreditación de la experiencia, lo primero que hay que tener en cuenta es que se trata de un proceso individualizado, cuyas actuaciones se deben ajustar a los principios de justicia, transparencia, calidad y viabilidad. Pero no sólo eso: también se insiste en que las pruebas sean válidas y fiables, de tal forma que en todo momento quede clara la diferencia entre experiencia y competencia, ya que lo que se evalúa no es la experiencia en sí, sino las competencias que se han podido adquirir a lo largo de la vida, durante esa experiencia. Pero veamos con más detalle los elementos que intervienen en los sistemas de acreditación, así como los documentos y sus fases.

\subsection{Elementos que intervienen}

Ya hemos comentado antes que no es lo mismo evaluar la formación impartida (la enseñanza) que evaluar las competencias adquiridas (los aprendizajes). La evaluación de la formación impartida se hace en base a un programa de enseñanza articulado en objetivos y contenidos, y la información sobre su adquisición se obtiene mediante la relación profesor-alumno, por medio del seguimiento de los estudiantes, o a través de exámenes.

Sin embargo, la evaluación de las competencias adquiridas se hace en base a un referente donde se definen las competencias y las realizaciones profesionales, competencias y realizaciones profesionales sobre las que hay que obtener evidencias (indirectas o directas) que ponen de manifiesto que el solicitante de la acreditación las posee. Lo cual nos conduce a precisar con más detalle los elementos que intervienen en los procesos de evaluación de la competencia, a saber:

a) El referente. En todo proceso de evaluación profesional siempre hay un referente (el currículo y la correspondiente cualificación donde se define el perfil profesional), se trate de la evaluación de la experiencia o se trate de la evaluación de la formación. En el caso de la evaluación de la experiencia, el referente es el documento base que constituye el punto de mira con el que se trata de igualar (comparar) la competencia del candidato. Por tanto, el referente es el primer elemento de toda evaluación de la competencia; diríamos que es lo primero que tiene que hacer el evaluador: mirar el referente, es decir, ir a la cualificación profesional y ver en qué términos se define, qué competencias 
tiene que tener su poseedor, qué debe conocer y qué actitudes y valores están asociados a dicho perfil profesional. El problema con el que nos encontramos es que el referente, tal como se publica en el boletín correspondiente, no nos sirve para contrastar con él la competencia del candidato, por su excesiva amplitud. Por ello, una de las primeras operaciones que tienen que hacer los evaluadores es elaborar lo que se conoce como la Guía de Evidencias, que acaba funcionando como una especie de adaptación curricular en la que, por cada una de las competencias del título, se hace constar las dimensiones o componentes de las competencias que deben ser evaluados.

b) El candidato y sus competencias. Una vez precisado el referente, el segundo elemento de toda evaluación es la persona que se evalúa; en nuestro caso el candidato que ha solicitado la evaluación para la acreditación. La competencia de este candidato es lo que se pretende evaluar, el objeto de la evaluación. Debe quedar claro, como hemos señalado anteriormente, que hablamos de la competencia en un sentido amplio, que incluye sobre todo las realizaciones profesionales, pero también una serie de conocimientos, actitudes y valores, que se supone implícitos en los estándares de competencias, es decir, subyacen en las actividades de trabajo y permiten comprender el porqué de determinados resultados.

c) La evidencia y las clases de evidencia. Entendemos por evidencia la información que necesitamos para comprobar que el candidato posee las competencias que le hacen acreedor de una certificación o de una titulación profesional. Hablamos por tanto de la evidencia de la competencia, que ya hemos dicho antes que tiene tres dimensiones o componentes: evidencia del saber hacer (evidencia de realizaciones), evidencia del saber (evidencia de conocimientos), evidencia del ser, estar y convivir (evidencia de actitudes). Existen muchas formas de obtención de tales evidencias: la observación del trabajador en el puesto de trabajo, el análisis de productos o resultados del trabajo, pruebas de simulación, testimonios de testigos, registros de audio-vídeos, informes de empleadores, documentos que certifiquen los años de experiencia laboral, certificados sobre la formación recibida, entrevistas con el solicitante, pruebas escritas, cuestionarios, etc.

\subsection{Documentos y fases}

Es evidente que se trata de un proceso complejo que supone el uso de determinados documentos y protocolos que le aportan rigor y validez a todo proceso de evaluación que se proponga reconocer y acreditar la experiencia. Normalmente se utilizan dos tipos de documentos: unos son de consulta y otros funcionan como protocolos que guían el quehacer en cada una de las fases. Entre los documentos de consulta hay dos que son imprescindibles: la Guía de Evidencias, de la que ya 
hemos hablado anteriormente, donde por cada titulación constan las evidencias clave en relación con cada una de las Unidades de Competencia; y el Manual de Orientación y Evaluación, donde se explica con todo detalle los pasos a seguir durante todo el proceso que dura el sistema de acreditación.

Pero además de los documentos de consulta, en la mayoría de las experiencias se utilizan otros documentos que funcionan como protocolos que hay que cumplimentar a lo largo del desarrollo:

a) El cuestionario. Se trata de un conjunto de preguntas que contesta el candidato sobre cada una de las competencias de la titulación. Tiene dos finalidades principales: una, que el candidato analice su propia trayectoria laboral y su grado de autonomía en el desempeño; dos, que se identifiquen las competencias con sus posibles evidencias.

b) El dosier de competencias. Es un documento pensado para que el candidato, asesorado por el orientador, pueda organizar y sistematizar la documentación (certificados, informes, títulos, certificados, etc.) que se va a utilizar como diferentes evidencias que avalan las competencias que ha podido adquirir a lo largo de su trayectoria profesional.

c) El informe de orientación. Es un instrumento creado para guiar la actuación del orientador, donde, a la luz de la información obtenida del cuestionario, del dosier de competencias y de diferentes entrevistas, se establece cuáles son las Unidades de Competencia que el candidato solicita que se le acrediten. En dicho informe se precisan tanto las Unidades de Competencia que presentan evidencia suficiente como las que no la presentan.

d) El informe de evaluación. Es un documento donde se hace constar el dictamen del equipo de evaluación sobre la suficiencia de las evidencias que hace el orientador. A continuación, para aquellas Unidades de Competencia cuya acreditación se solicita, pero no presentan evidencia suficiente, se elabora el plan de obtención de evidencias, con la finalidad de obtener, mediante diferentes medios, nuevas evidencias sobre la competencia del candidato. Finalmente en el informe de evaluación se incluye un acta donde consta la relación de las Unidades de Competencia indicando si han sido o no acreditadas.

e) El plan de formación. El proceso de acreditación de la competencia termina con un plan de formación que se elabora entre los profesionales que intervienen y el propio candidato. La finalidad de este plan es definir la formación que precisa el solicitante e incorporarlo a algún circuito de formación para que adquiera aquellas competencias que no han sido acreditadas.

La cumplimentación de todos estos documentos y protocolos se lleva a cabo durante un proceso muy regulado y un tiempo variable, que en algunos países llega hasta los tres o cuatro meses. Como podemos deducir por la función de los documentos citados, desde el punto de vista técnico-educativo, se distinguen dos 
fases principales en los procesos de acreditación de la experiencia: una es la fase de orientación, donde un orientador obtiene las primeras evidencias indirectas sobre las competencias del solicitante de la acreditación que le permiten decidir si está en condiciones de pasar a la fase siguiente; y la otra es la fase de evaluación, donde un equipo de evaluadores evalúa si el candidato presenta suficientes evidencias acerca de sus competencias.

No obstante, dado que se trata de un proceso complejo y que lleva consigo acciones previas y posteriores a la evaluación de la competencia, es por ello por lo que en la mayoría de los países que están desarrollando sistemas de acreditación de competencias se suele seguir un proceso que, en términos generales, pasa por las siguientes fases:

1. $\left.{ }^{a}\right)$ Información e inscripción. La primera fase es de información en dos sentidos. En primer lugar se informa a la opinión pública sobre la o las titulaciones que van a someterse al proceso de reconocimiento; y en segundo lugar se informa al candidato sobre las condiciones y requisitos para participar, así como sobre los posibles resultados.

2. ${ }^{\text {) }}$ Orientación. Una vez realizada la inscripción, se inicia el proceso de asesoramiento consistente en orientar al candidato para que supere la fase de evaluación. Para ello el orientador ayuda al candidato a elaborar su dosier de competencias y a cumplimentar los cuestionarios previos de evaluación de competencias. Esta fase termina con el informe que elabora el orientador y entrega al evaluador en la fase siguiente. En caso de que el orientador considere que el candidato no está en condiciones para pasar a la fase de evaluación, le deriva al sistema educativo para que complete su formación.

3. ${ }^{\text {) }}$ Evaluación. Durante esta fase lo primero que hace el equipo de evaluación es analizar el informe del orientador, apoyándose en el dosier de competencias y en los cuestionarios que ha respondido el candidato. Como resultado de este análisis el equipo de evaluación decide qué competencias están suficientemente acreditadas en la fase de orientación y cuáles no. A continuación se diseña el plan de obtención de evidencias para aquellas competencias no acreditadas en la fase de orientación y se lleva a cabo.

4. $\left.{ }^{a}\right)$ Certificación de las competencias. Una vez realizado el plan de obtención de evidencias el equipo de evaluación vuelca los resultados en el acta, certificando las competencias que el candidato haya acreditado tanto en la fase de orientación como en la fase de evaluación e informa de ello al candidato. Puede suceder que al candidato se le certifiquen todas las competencias de una titulación (hablaríamos en este caso de acreditación total) o que sólo se le certifiquen algunas competencias (acreditación parcial).

5. ${ }^{a}$ Itinerario formativo. En caso de que el candidato no haya podido acreditar la totalidad de las competencias de la titulación, se le orienta sobre la formación 
que le puede conducir a completar las competencias que le faltan, lo que se concreta con todo detalle en el plan de formación.

\section{LOS SISTEMAS DE ACREDITACIÓN EN OTROS PAÍSES}

Desde hace algo menos de una década, podemos decir que prácticamente en todos los países desarrollados funcionan los sistemas de reconocimiento y acreditación de las competencias y en todos los casos se trata de una regulación legal específica que se desarrolla al amparo de lo que en cada país se denomina Sistema Nacional de las Cualificaciones y Formación Profesional.

Una amplia información sobre cómo funcionan, las normas que los regulan, las fases a seguir, los procedimientos y los recursos la encontramos en tres informes: uno elaborado por el INCUAL (2003), otro por el MECD (2003) y el tercero por la Comisión Europea (2001b). En estos documentos encontramos información sobre los sistemas de acreditación en los siguientes países: Reino Unido, Francia, Bélgica, Alemania, Grecia, España, Italia, Portugal, Noruega, Holanda, Finlandia, Suecia y Dinamarca, así como también en Estados Unidos, Australia, Canadá, Nueva Zelanda y Sudáfrica, en cuyas páginas web se informa ampliamente de sus propios dispositivos para acreditar.

En esta perspectiva internacional vamos a destacar dos cuestiones que nos parecen relevantes: una es el papel que han jugado los organismos internacionales y la cultura que han acabado creando sobre los sistemas de acreditación; dos, comentaremos el caso particular que está representando, sobre todo en países como Francia, la acreditación en el ámbito universitario.

\subsection{Organismos internacionales y los sistemas de acreditación}

La UNESCO, la Unión Europea, la OCDE y la OIT son los principales organismos internacionales que se vienen ocupando de los sistemas de reconocimiento y acreditación de las competencias adquiridas mediante vías no formales o mediante la experiencia. Los informes o documentos que han publicado estas instituciones son de diverso tipo. Veamos los más relevantes.

Por parte de la Organización de las Naciones Unidas para la Educación, la Ciencia y la Cultura (UNESCO), algunos documentos que explícitamente entran en este asunto son los siguientes: el documento final sobre la Cuarta Conferencia Internacional de Educación de Adultos. Informe final, publicado en el 1985; la Declaración de Hamburgo sobre la Educación de Adultos (1997a); el Plan de acción para el futuro de la Educación de Adultos (1997b) y el informe sobre la Quinta Conferencia Intergubernamental de Educación de Adultos (1997c); el libro dirigido por Delors, La educación encierra un tesoro (1996); también en la Sexta Conferencia sobre Educación de Adultos (CONFINTEA-VI) que se va a celebrar en Brasil en 2009 está previsto que se trate la acreditación de competencias en el marco del aprendizaje a lo largo de la vida. 
Por parte de la Comisión Europea la documentación es abundante, pero baste reseñar la siguiente: el libro titulado Enseñar y aprender. Hacia la sociedad del conocimiento. Libro Blanco (1996); el documento que lleva por título Memorándum sobre el aprendizaje permanente (2000); el informe sobre el aprendizaje titulado Hacer realidad un espacio europeo del aprendizaje permanente (2001a); el documento publicado por CEDEFOP y EURIDICE cuyo título es Iniciativas nacionales para promover el aprendizaje a lo largo de la vida (2001b); un breve documento titulado Principios para la identificación y validación de los aprendizajes no formales e informales (2004); y la Directiva 2005/36/CE del Parlamento Europeo y del Consejo, de 7 de septiembre de 2005 relativa al reconocimiento de cualificaciones profesionales (2005).

La Organización para la Cooperación y el Desarrollo Económicos (la OCDE) también cuenta con documentos sobre el tema. Algunos a los que hemos tenido acceso son los siguientes: un informe elaborado por el Comité de Educación bajo el título The role of National Qualifications Systems in promoting lifelong learning (2001); otro sobre Points-dès des debats et tendences nationales dans les systèmes de qualifications. Résumés par pays (2002); y otro más general dedicado a la Educación de Adultos, cuyo título es Más allá de la retórica: políticas y prácticas del aprendizaje de las personas adultas (2003).

Finalmente, también la Organización Internacional del Trabajo (OIT) ha abordado el sistema de reconocimiento y acreditación de las competencias, unas veces con ocasión de tratar un tema más general, como vemos en el documento Aprender y formarse para trabajar en la sociedad del conocimiento (2002); y otras veces de forma más específica, en la Resolución 195, de junio de 2004 sobre la formación y el aprendizaje permanente (2004).

No obstante, más que la reseña de los propios documentos, lo que nos interesa de estos organismos internacionales es lo que dicen (la cultura que han creado) sobre los sistemas de acreditación de las competencias adquiridas mediante vías no formales e informales. A título de selección de lo que nos ha parecido más importante y corriendo el riesgo de resultar simplificador, podemos decir que, en general y con más o menos intensidad, todos estos organismos destacan en sus documentos y publicaciones lo siguiente sobre los sistemas de acreditación de la competencia:

a) Que los sistemas de reconocimiento de la competencia, para buena parte de los países que los llevan a cabo, están representando el gran reto de la educación del siglo XXI.

b) En cualquier caso siempre se conciben y se consideran como un eficaz mecanismo compensatorio de lucha contra la exclusión.

c) Desde el punto de vista del propio trabajador, estas prácticas educativas constituyen un medio efectivo de encontrar empleo y mantenerlo.

d) También estamos ante una forma de conciliar y ajustar en mejores condiciones la oferta y la demanda de empleo en el mercado laboral. 
e) Todos los documentos insisten en que tales sistemas de acreditación facilitan la transferencia de títulos en el mercado laboral global y la movilidad de los trabajadores.

f) Tal vez sea ésta la afirmación más consistente y repetida en tales documentos: que estamos ante la mejor estrategia para promover el aprendizaje a lo largo de la vida.

g) No son pocos los documentos que se refieren a que tales sistemas de acreditación estén alumbrando una nueva función de los profesionales de la educación.

h) En la práctica educativa está sucediendo que el peso de la validación de la experiencia en el sistema educativo está obligando a cambiar el modo en que se imparte la formación.

i) Finalmente, conviene destacar el hecho de que en algunos países, como en Francia, la acreditación de las competencias se reconoce como un derecho de los ciudadanos.

\subsection{La acreditación en el ámbito universitario}

Algunos países ya tienen una cierta tradición de acreditar en el ámbito universitario los aprendizajes no formales e informales. Esto ocurre a pesar de que la universidad siempre ha sido más reticente al reconocimiento de aprendizajes adquiridos al margen de la enseñanza ofrecida por los docentes. La cultura académica del profesorado y su convicción de que sólo el aprendizaje adquirido a través de la enseñanza es el que está lo suficientemente ordenado y estructurado como para ser utilizado con éxito han retrasado la expansión de este tipo de prácticas en las universidades. A veces son también cuestiones de tipo económico y la gestión de pago por créditos de formación las que oscurecen las razones que deberían conducir a reconocer y acreditar con más normalidad el conocimiento y las competencias ya adquiridas y suficientemente mostradas y demostradas (Inchauspé, 1999, 69).

El reconocimiento en la universidad de aprendizajes adquiridos en la experiencia se refiere a tres clases de aprendizajes que pueden ser objeto de acreditación: por un lado, están todos aquellos conocimientos y competencias preuniversitarias que se consideran necesarios para tener acceso a los estudios universitarios; por otra parte, también se acreditan los conocimientos universitarios que se han aprendido en otras universidades (sobre todo extranjeras); pero también la acreditación universitaria se refiere a los conocimientos, equivalentes a los universitarios, que se han adquirido fuera de cualquier sistema universitario.

El reconocimiento o acreditación de competencias y conocimientos preuniversitarios depende del modelo de acceso a la universidad que tenga cada sistema universitario o incluso cada universidad. Existen dos modelos muy distintos: unos que son muy exigentes en el acceso y poco en el proceso y otros, en cambio, son más flexibles en los requisitos de entrada pero cuidan más todo el proceso de 
aprendizaje una vez dentro. Algunas universidades tienen un modelo de acceso muy rígido y exigente desde el punto de vista académico como, por ejemplo, el de las universidades españolas, pero otras universidades son mucho más flexibles en el acceso y más exigentes y cuidadosas del proceso de estudio. En España es difícil entrar en la universidad como estudiante: además de poseer el título de Bachiller, hay que superar unas pruebas de selectividad. A las personas mayores de 25 años se les dispensa del Bachiller (no se les concede dicho título) y de las pruebas de selectividad si aprueban un examen específico de acceso para mayores de 25 años que mimetiza en gran medida las pruebas de selectividad. Es una prueba, por otra parte, que sigue manteniendo como referente más el currículo de Bachillerato que lo que los adultos han podido aprender en la experiencia. Otras universidades son más flexibles en el acceso permitiendo estudiar en la universidad a todos aquellos que cuentan con las competencias realmente necesarias para poder seguir estudios universitarios aunque no todas ellas coincidan con las competencias que se aprenden en los estudios reglados preuniversitarios. En todo caso, si alguna competencia no está suficientemente fortalecida, por ejemplo, idioma extranjero, se atiende en el proceso de aprendizaje universitario sin mayores problemas.

En cuanto al reconocimiento y acreditación de conocimientos adquiridos en la experiencia por créditos de las carreras universitarias existen también varios modelos. Lo más frecuente es que solamente una parte del título universitario pueda ser adquirida mediante la acreditación de aprendizajes no formales e informales pero no la totalidad del título. Así ocurre en Canadá, donde pueden ser acreditados hasta dos tercios del título universitario. En España, las universidades están comenzando a conceder créditos de libre configuración por aprendizajes adquiridos en sistemas de formación no formal, como cursos de verano o cursos de extensión universitaria, e incluso, por participar en actividades o tener responsabilidades universitarias. Este modelo de acreditación parcial ha cambiado últimamente en Francia con la Ley de Modernización Social del 17/01/02 según la cual una universidad puede acreditar la totalidad de un título universitario mediante el reconocimiento y la acreditación de aprendizajes adquiridos tanto en la experiencia laboral como en la experiencia en actividades de voluntariado.

El reconocimiento de los aprendizajes adquiridos en otros centros universitarios, sobre todo extranjeros, es lo que más viene preocupando a las universidades de las distintas regiones del mundo y particularmente a las europeas desde que, en 1999, suscribieron la Declaración de Bolonia con el fin de crear un único Espacio Europeo de Educación Superior. En realidad en Europa desde hace tiempo las universidades reconocen los créditos adquiridos en otros centros universitarios, como se pone de manifiesto en el programa Erasmus. Precisamente por ello, en los últimos años las energías se están empleando en generar un sistema común de acreditación de aprendizajes adquiridos en cualquiera de las universidades del espacio europeo. No obstante hay que reconocer que también en Europa, y sobre todo en Francia, se está avanzando en la acreditación universitaria de aprendizajes no formales adquiridos fuera de las universidades. 
En el ámbito del espacio americano uno de los países donde la universidad está más adelantada sobre el reconocimiento de aprendizajes adquiridos fuera de la universidad es Canadá. En el año 2000, el Consejo Superior de Educación impulsó una apertura oficial para acoger a candidatos distintos de aquellos que provienen del sistema educativo preuniversitario, es decir, para acoger a los técnicos que han estudiado formación profesional en los CEGEPS, a los que han estudiado en el extranjero y a las personas adultas que han hecho su currículo al margen del sistema de enseñanza. La Asociación Canadiense de Educación de Adultos de las Universidades de Lengua Francesa (ACDEAULF), que agrupa a dieciocho establecimientos universitarios, reconoce que ha habido un avance en este aspecto aunque no cuenta con información detallada y sistemática sobre este tipo de prácticas universitarias así como sobre los dispositivos y procesos empleados. En el año 2005 esta asociación recibió una subvención del Ministerio de Educación para estudiar precisamente la situación del reconocimiento en las universidades (ACDEAULF, 2005).

Se sabe que en las universidades canadienses de Sherbrooke y de Montreal el reconocimiento de los aprendizajes adquiridos en la experiencia constituye una práctica habitual desde hace tiempo, de tal forma que hasta dos tercios de los créditos exigidos en un diploma pueden ser reconocidos a toda persona, candidata al reconocimiento de sus aprendizajes, que demuestre haber conseguido los objetivos de dichos créditos. La Universidad de Quebec está igualmente abierta a los aprendizajes adquiridos fuera del sistema de enseñanza.

En el ámbito europeo hay que resaltar la experiencia de las universidades francesas en la aplicación de dispositivos de reconocimiento y acreditación de aprendizajes adquiridos en la experiencia. En Francia las universidades están obligadas por ley a atender cualquier solicitud de reconocimiento y acreditación de aprendizajes adquiridos en la experiencia. A pesar de la fuerza de la ley, muchas universidades se siguen resistiendo a este tipo de prácticas. Otras en cambio como, por ejemplo, la Universidad París VIII (Vincennes-Saint Denis) lo tienen integrado en su estructura y lo incluyen como uno de los servicios que se explican en la Guía del Estudiante. Además esta Universidad dispone de verdaderos especialistas en acreditación de aprendizajes no formales, que han generado un interesante marco teórico sobre la relación experiencia-formación (Bézille y Courtois, 2006) y están aplicando dispositivos y procedimientos a seguir en el proceso de validación que emplea a todo un departamento de profesores y que se ha convertido en referente de este tipo de prácticas en la universidad europea. La revista Pratiques de Formation de la misma Universidad ha dedicado varios monográficos al este tema (Meyer et al., 1987; Aubret et al., 1989, 1992; VV.AA., 2001).

En España, la última legislación sobre la reforma universitaria, la Ley Orgánica 4/2007 por la que se modifica la Ley 6/2001 de 21 de diciembre, de Universidades, añade un nuevo apartado (el 4) al artículo 43 en el que se explicita la voluntad de aplicar el reconocimiento de aprendizajes no formales en los siguientes términos: 
Para facilitar la actualización de la formación y la readaptación profesionales y la plena y efectiva participación en la vida cultural, económica y social, el Gobierno, previo informe del Consejo de Universidades, regulará los procedimientos para el acceso a la universidad de quienes, acreditando una determinada experiencia laboral o profesional, no dispongan de la titulación académica legalmente requerida al efecto con carácter general. A este sistema de acceso, que permitirá el ingreso en cualquier universidad, centro y enseñanza, podrán acogerse también, en las condiciones que al efecto se establezcan, quienes, no pudiendo acreditar dicha experiencia, hayan superado una determinada edad.

La voluntad de sobrepasar las prácticas tradicionales del examen de acceso a la universidad para mayores de 25 años parece, de esta forma, abrir la posibilidad a nuevas prácticas más amplias y acogedoras de cualquier tipo de aprendizajes adquiridos en la experiencia que lo que está siendo la práctica del examen de acceso para mayores de 25 años que se viene practicando en España desde el año 1971.

Por otra parte, también en la misma ley, en el artículo 36 dedicado, entre otras cosas, a validación de la experiencia, se establece que el Gobierno, previo informe del Consejo de Universidades, regulará, entre otras cosas, «d) Las condiciones para validar, a efectos académicos, la experiencia laboral o profesional». Cabe esperar, pues, más pronto que tarde, que el Gobierno y el Consejo de Universidades definan tales condiciones para la validación de la experiencia en nuestras universidades.

\section{Los Sistemas de ACREDITACIÓN EN ESPAÑa}

En todos los países donde funcionan los sistemas de acreditación de la experiencia está claro que tales sistemas tienen que estar legalmente regulados. Ello es así porque la acreditación afecta a los títulos de las enseñanzas formales, que ya cuentan con su propia regulación legal; por tanto, las mismas autoridades educativas que han regulado las enseñanzas formales son las que tendrán que regular legalmente los sistemas de acreditación.

En este sentido, en España sucede lo mismo que en otros países. Aunque se ha incorporado tarde a estos nuevos procedimientos educativos, hay que reconocer que se han dado pasos firmes y ya contamos con suficiente legislación sobre estos sistemas de acreditación. A continuación haremos un recorrido por la legislación que se ha publicado hasta ahora y comentaremos dos experiencias de acreditación que nos parecen importantes: el proyecto ERA y la experiencia de Canarias.

\subsection{El reconocimiento de lo adquirido en la legislación española}

Si consideramos la acreditación en un sentido amplio, nos encontramos con un número importante de textos legales que regulan estos sistemas en diferentes 
ámbitos y contextos educativos: en los ámbitos de las enseñanzas formales y no formales y en los contextos de la Formación Básica y Formación Profesional. Las reseñamos a continuación por orden cronológico.

- Pruebas de acceso a la Universidad (1970). El acceso a la Universidad, sin contar con el título de Bachillerato como condición previa, se regula por primera vez en la Ley General de Educación (LGE, 1970) y posteriormente se mantiene en la Ley Orgánica de Ordenación General del Sistema Educativo (LOGSE, 1990), la Ley Orgánica de la Calidad de la Educación (LOCE, 2002) y en la Ley Orgánica de la Educación (LOE, 2007) en los capítulos dedicados a la educación de las personas adultas. Hay que tener en cuenta que, tal como se regula este acceso a la universidad, en un sentido amplio podemos decir que se trata de sistemas de acreditación, pues de alguna forma esto puede entenderse como una pasarela que da paso a quienes han adquirido determinados aprendizajes para poder ingresar en la universidad, aunque no han realizado curso alguno de Bachillerato.

- Pruebas libres de las titulaciones formales (1990). Se regulan en las últimas leyes que se ocupan de la reforma general del sistema educativo: la LOGSE, la LOCE y la LOE. Así pues, con el requisito de poseer una determinada edad, mediante pruebas únicas se puede obtener el título de Graduado en Educación Secundaria, el título de Bachillerato y cualquiera de los títulos de Formación Profesional Específica. Conviene aclarar que, para titular, no es lo mismo superar un sistema de acreditación que superar una prueba. No obstante, aquí como en el caso anterior, también podemos hablar de sistemas de acreditación en sentido amplio, toda vez que se admite que para titular no es necesario haber pasado por el circuito escolar.

- Acreditación de enseñanzas parciales de Canarias (1997). Una orden del Gobierno de Canarias dispensa de la condición de acceso, mediante sistemas de acreditación, a los trabajadores que deseen seguir las enseñanzas de formación profesional específica. Se hace mediante la Orden de 3 de julio de 1997 por la que se regula con carácter experimental las enseñanzas parciales de Formación Profesional (BOC de 1 de agosto de 1997).

- Acreditación de la Formación Básica de Canarias (1998). Se trata de la única legislación española que regula la acreditación en el campo de la formación básica de las personas adultas. La norma que lo regula es el Decreto 79/1998, de 28 de mayo, por el que se establece el Currículo de la Formación Básica para la Educación de las Personas Adultas (BOC de 12 de junio de 1998). Los dos principales recursos que crea este Decreto son el Sistema de Acreditación Formativa (SAF), mediante el cual se valora la experiencia y la educación no formal; y la Valoración Inicial del Alumno (VIA) que se realiza en el momento de la matrícula de los alumnos para reconocerles en términos de créditos los aprendizajes que ya tienen adquiridos.

- Acreditación de las cualificaciones profesionales (2002). La Ley Orgánica 5/2002, de 19 de junio, de las Cualificaciones y de la Formación Profesional 
(BOE de 20 de junio de 2002) es la primera ley orgánica que a nivel del Estado regula el reconocimiento y acreditación de las competencias adquiridas a través de la educación no formal y mediante la experiencia en el campo de la Formación Profesional. Concretamente en el artículo 8, bajo el epígrafe "Reconocimiento, evaluación, acreditación y registro de las cualificaciones profesionales", plantea que la evaluación y la acreditación de las competencias profesionales adquiridas a través de la experiencia laboral o de vías no formales de formación tendrá como referente el Catálogo Nacional de Cualificaciones Profesionales y se desarrollará siguiendo criterios que garanticen la fiabilidad, la objetividad y rigor técnico (art. 8.2). Además en el mismo artículo se establece que la acreditación puede ser total, pudiendo dar lugar al título, o parcial, en cuyo caso sólo se certifican determinadas competencias de un título (art. 8.3).

- Acreditación para los Certificados de Profesionalidad (2003). En el ámbito de las enseñanzas no formales y regulados por el Ministerio de Trabajo se ha publicado el Real Decreto 1506/2003, de 28 de noviembre, por el que se establecen las directrices de los certificados de profesionalidad (BOE n. 302 , de 18.12.2003). En este decreto, al hablar de las condiciones para el acceso al certificado de profesionalidad, también se tienen en cuenta las competencias profesionales adquiridas mediante la experiencia laboral u otras vías de aprendizaje no formales.

- Acreditación en la Ley de Educación de Adultos de Canarias (2003). En esta ley, aprobada por el Parlamento de Canarias, se plantea la acreditación como un recurso, un principio educativo y una línea programática en el campo de la formación de las personas adultas. Se trata de la Ley 13/2003, de 4 de abril, de Educación y Formación Permanente de Personas Adultas de Canarias (BOC de 25 de abril de 2003).

- Dispositivo de acreditación del País Vasco (2004). En el País Vasco, el organismo encargado de la evaluación y la acreditación es la Agencia Vasca para la Evaluación de la Competencia y la Calidad de la Formación Profesional. La norma que lo regula es el Decreto 70/2004, de 27 de abril, por el que se regulan las pruebas para la obtención de los Títulos de Técnico y Técnico Superior de Formación Profesional Específica (BOPV de 5 de mayo de 2004).

- Modelo catalán de acreditación (2004). La normativa catalana que regula todo el proceso de acreditación se basa, por un lado, en la Ley 17/2002, de 5 de julio, de ordenación del Sistema de Ocupación y de creación del Servicio de Ocupación de Cataluña (DOGC de 12 de julio de 2002), y, por otra parte, en el Decreto 176/2003, de 8 de julio, de creación del Instituto Catalán de las Cualificaciones Profesionales (DOGC de 29 de julio de 2003).

- Acreditación en la LOE (2006). Ya hemos comentado antes que la Ley Orgánica 5/2002 es la primera ley española que regula el reconocimiento y acreditación, pero en el campo de la Formación Profesional. Sin embargo, la primera vez que una ley reguladora del sistema educativo se ocupa de la valoración de los aprendizajes adquiridos a través de la experiencia es la Ley Orgánica 
2/2006, de 3 de mayo, de Educación (LOE) (BOE de 4 de mayo de 2006). En el capítulo dedicado a la educación de las personas adultas, concretamente en el artículo 66.4, se afirma: "Las personas adultas pueden realizar sus aprendizajes tanto por medio de actividades de enseñanza, reglada o no reglada, como a través de la experiencia, laboral o en actividades sociales, por lo que se tenderá a establecer conexiones entre ambas vías y se adoptarán medidas para la validación de los aprendizajes así adquiridos".

- Acreditación en la LOU (2007). En el ámbito universitario, ya lo hemos comentado antes, la validación de la experiencia laboral se regula por primera vez en la Ley Orgánica 4/2007, de 12 de abril, por la que se modifica la Ley Orgánica 6/2001, de 21 de diciembre, de Universidades (BOE de 13 abril de 2007). Expresamente en el artículo 36, dedicado, entre otras cosas, a la validación de experiencia, se dice: «El Gobierno, previo informe del Consejo de Universidades, regulará: d) Las condiciones para validar, a efectos académicos, la experiencia laboral o profesional".

- $\quad$ El dispositivo de acreditación de la Formación Profesional de Canarias (2007). Contando ya con casi una década de experiencia de acreditación de la Formación Básica de las personas adultas, el Gobierno de Canarias se decide a regular el reconocimiento y acreditación de la experiencia laboral en el campo de la Formación Profesional, comenzando con una experiencia piloto. La norma que regula esta experiencia es la Orden de 23 de abril de 2007, por la que se establece para el año 2007, con carácter experimental y limitado, el procedimiento de reconocimiento, evaluación y acreditación de competencias del Título de Técnico en Cocina, adquiridas por la experiencia laboral o el aprendizaje no formal (BOC n. ${ }^{\circ} 111$ del martes 5 de junio de 2007).

La legislación anteriormente reseñada pone de manifiesto la diversidad de experiencias de acreditación que se vienen desarrollando en nuestro país, pero para este trabajo sólo vamos a comentar dos de esas experiencias: una que se desarrolla a nivel del Estado, sobre acreditación en el campo de la Formación Profesional; y otra que tiene lugar en Canarias, sobre acreditación en el campo de la Formación Básica.

\subsection{El proyecto ERA: acreditación de la Formación Profesional}

Ya hemos comentado antes que el primer texto legal que a nivel del Estado regula el reconocimiento y acreditación de las competencias adquiridas a través de la educación no formal y mediante la experiencia en el campo de la Formación Profesional es la Ley Orgánica 5/2002, de 19 de junio, de las Cualificaciones y de la Formación Profesional (BOE del 20 de junio 2002). A partir de la publicación de esta ley, el Gobierno del Estado y algunas Comunidades Autónomas, de acuerdo con los artículos 8.2, 8.3 y 8.4 de la citada ley, deciden llevar a cabo una experiencia que permitiera poner a prueba la complejidad que suponía abordar un proceso de esta envergadura y definir al mismo tiempo, un procedimiento, unos recursos y unos criterios de calidad compartidos. 
Para ello se pone en marcha el Proyecto experimental para la evaluación, reconocimiento y acreditación de las competencias profesionales (Proyecto ERA) (MECD, 2003), en el que con financiación del Fondo Social Europeo participan el Ministerio de Educación, Cultura y Deportes, el Ministerio de Trabajo y Asuntos Sociales y siete Comunidades Autónomas (Andalucía, Castilla-La Mancha, Galicia, Murcia, Navarra, País Vasco y Valencia).

Según el Grupo Técnico de Trabajo del Proyecto ERA (2004), la experiencia, desarrollada durante los años 2003-2004, permitió la definición de conceptos y principios sobre los sistemas de acreditación y también facilitó el uso de instrumentos y protocolos de actuación.

Los resultados obtenidos fueron altamente satisfactorios como podemos ver en la Tabla 1: de un total de 302 candidatos que solicitan acreditación para una serie de titulaciones (como vemos en la columna de la izquierda), obtiene acreditación completa el 78\% y parcial el 12\%.

Tabla 1. Resultados del Proyecto ERA (2003-2004)

\begin{tabular}{|l|c|c|c|c|}
\hline \multicolumn{1}{|c|}{ Referente profesional } & Comienzan & $\begin{array}{c}\text { Acreditación } \\
\text { completa }\end{array}$ & $\begin{array}{c}\text { Acreditación } \\
\text { parcial }\end{array}$ & $\begin{array}{c}\text { Sin } \\
\text { acreditación }\end{array}$ \\
\hline Cocina & 45 & 41 & 3 & 1 \\
\hline Restaurante y bar & 20 & 2 & 5 & 13 \\
\hline Carrocería & 45 & 43 & 2 & 0 \\
\hline Mantenimiento e Instalaciones & 40 & 20 & 16 & 4 \\
\hline Instalaciones singulares/Electricidad & 42 & 24 & 4 & 14 \\
\hline Asistencia domiciliaria & 38 & 38 & 0 & 0 \\
\hline Peluquería & 27 & 22 & 5 & 0 \\
\hline Jardinería & 21 & 21 & 0 & 0 \\
\hline Solador/Alicatador & 24 & 24 & 0 & 0 \\
\hline TOTALES & 302 & 235 & 35 & 32 \\
\hline
\end{tabular}

Fuente: Grupo Técnico de Trabajo del Proyecto Era $(2004,71)$.

\subsection{La experiencia de Canarias: acreditación de la Formación Básica}

También hemos comentado antes que la única legislación española que ha regulado los sistemas de acreditación en el campo de la Formación Básica (conducente al título de Graduado en Educación Secundaria) ha tenido lugar en Canarias. Esto lo ha realizado el Gobierno del Archipiélago mediante el Decreto 79/1998, de 28 de mayo, por el que se establece el Currículo de la Formación Básica para la Educación de las Personas Adultas (BOC de 12 de junio de 1998).

Los dos principales recursos que crea este Decreto son el Sistema de Acreditación Formativa (SAF), que permite valorar la experiencia y la educación no formal; 
y la Valoración Inicial del Alumno (VIA) que se realiza en el momento de la matrícula de los alumnos para reconocerles en términos de créditos los aprendizajes que ya tienen adquiridos.

Tabla 2. Resultados de la aplicación del sistema de acreditación de la Formación Básica en los centros públicos de Canarias. Primer cuatrimestre del curso 2005-2006

\begin{tabular}{|l|c|c|c|}
\hline Formación Básica de Personas Adultas & Matriculados & $\begin{array}{c}\text { Valorados } \\
\text { por la VIA }\end{array}$ & \% de valorados \\
\hline Formación Básica Inicial & 2.599 & 1.367 & 52,6 \\
\hline 1) Alfabetización & 1.093 & 810 & 74,1 \\
\hline 2) Neolectores & 1.378 & 815 & 59,1 \\
\hline 3) Enseñanza Ordinaria & 1.221 & 552 & 45,2 \\
\hline Formación Básica Post-inicial & 6.792 & 4.488 & 66,1 \\
\hline 4) Consolidación & 2.401 & 1.590 & 66,2 \\
\hline 5) Avanzado & 2.110 & 1.383 & 65,5 \\
\hline 6) Titulación & 2.281 & 1.515 & 66,4 \\
\hline TOTAL FORMACIÓN BÁSICA & 9.391 & 5.855 & 62,3 \\
\hline
\end{tabular}

Fuente: Medina $(2007,49)$.

Debe quedar claro que en este caso hablamos de acreditación en sentido estricto, toda vez que, en relación con los objetivos y contenidos de las enseñanzas que conducen al título de Graduado en Educación Secundaria, se valora lo que una persona ha podido aprender a lo largo de su vida, independientemente de cómo, dónde y cuándo ha sido; y además se hace, no mediante una prueba única (como de hecho se regula en la LOGSE y posteriormente en la LOCE y la LOE), sino a través de un proceso continuo de evaluación por el que se van adquiriendo créditos para el título hasta un total de 200 créditos.

Los resultados sobre la acreditación de la Formación Básica en Canarias los vemos en la Tabla 2, donde un 62\% de los alumnos han sido evaluados mediante la VIA, lo que ha permitido, no sólo hacer justicia a estos alumnos al reconocérseles lo que ya saben, sino también situarles en el nivel más adecuado a las competencias y objetivos que ya poseen (Medina, 2007, 49).

\section{A MODO DE CONCLUSIÓN}

A lo largo de este artículo hemos querido poner de manifiesto la importancia teórica y práctica que, desde nuestro punto de vista, tienen los sistemas de acreditación prácticamente en todos los países desarrollados. No podemos pensar que hayan nacido fruto de la improvisación o de la propuesta de aventureros irresponsables, sino más bien como un medio para reducir las situaciones de exclusión social e implementar las políticas de empleo y, todo ello, en el horizonte 
más deseable para el futuro de la formación y del trabajo: crear una cultura de aprendizaje a lo largo de la vida. No en vano, para muchos autores e instituciones internacionales estamos ante un nuevo derecho de los ciudadanos y embarcados en lo que está representando el gran reto de la educación del siglo XXI.

Ya hemos visto que los sistemas de acreditación se aplican, desde hace algún tiempo, en el campo de la Formación Básica y también en el de la Formación Profesional, lo que nos conduce a pensar que ya contemos en nuestro país con experiencias suficientes y con conocimientos y teorías plausibles para seguir avanzando en la misma dirección. En los documentos de Bolonia se hacen algunos planteamientos, muy genéricos todavía, sobre la aplicación de tales sistemas en la Universidad, pero esperamos que en España, a partir del desarrollo del artículo 36 de la Ley Orgánica 4/2007 de Universidades (que prevé regular las condiciones para validar, a efectos académicos, la experiencia laboral o profesional), podamos avanzar en este sector de la educación, como ya se hace en otros países europeos.

Estamos convencidos de que, una vez que se sitúe este asunto en el ámbito universitario, se podrán ampliar las contribuciones dirigidas a optimizar la metodología, los medios y los recursos que se suelen emplear en estos sistemas de reconocimiento de la experiencia, pero, mejor todavía, surgirán aportaciones que entren en el fondo del debate para abordar tanto los problemas teóricos como prácticos que plantean tales prácticas educativas.

\section{REFERENCIAS BIBLIOGRÁFICAS}

ACDEAULF (2005) La reconnaissance des acquis dans les universités québécoises: état de la situation. Projet de recherche (Association canadienne d'éducation des adultes des universités de langue française). Montréal (Document remis lors du Colloque national sur la reconnaissance des acquis à Montréal le 7 avril 2005).

Aubret, J. y otros (1989) Reconnaissance des acquis et outils d'évaluation, en Pratiques de Formation (Collection Thématiques), Mars 1989. Université de Paris VIII.

Bajo, M. T.; Maldonado, A. et al. (2003) Las competencias en el nuevo paradigma educativo para Europa. Universidad de Granada, Vicerrectorado de Planificación, Calidad y Evaluación. (Consulta: 5-6-2007). Página web: www.ugr.es/ psicolo/docs_espacioeuropeo/analisis_de_competencias_europa.doc-

Bézille, H. y Courtois, B. (2006) Penser la relation expérience-formation. Lyon, Chronique Sociale.

BOC (1997) Orden de 3 de julio de 1997 por la que se regula con carácter experimental tales enseñanzas parciales de Formación Profesional. Santa Cruz de Tenerife. Boletín Oficial de Canarias (1 de agosto de 1997).

- (1998) Decreto 79/1998, de 28 de mayo, por el que se establece el currículo de la Formación Básica para la Educación de Personas Adultas. Santa Cruz de Tenerife. Boletín Oficial de Canarias (12 de junio de 1998). 
- (2003) Ley 13/2003, de 4 de abril, de Educación y Formación Permanente de Personas Adultas de Canarias. Santa Cruz de Tenerife. Boletín Oficial de Canarias (25 de abril de 2003).

- (2007) Orden de 23 de abril de 2007, por la que se establece para el año 2007, con carácter experimental y limitado, el procedimiento de reconocimiento, evaluación y acreditación de competencias del Título de Técnico en Cocina, adquiridas por la experiencia laboral o el aprendizaje no formal. Santa Cruz de Tenerife. Boletín Oficial de Canarias (5 de junio de 2007).

BOE (1970) Ley General de Educación. Madrid. Boletín Oficial del Estado (6 y 7 de agosto de 1970).

- (1990) Ley Orgánica 1/1990 de Ordenación General del Sistema Educativo. Madrid. Boletín Oficial del Estado (4 de octubre de 1990).

- (2002) Ley Orgánica 10/2002 de Calidad de la Educación. Madrid. Boletín Oficial del Estado (24 de diciembre de 2002).

- (2002) Ley Orgánica 5/2002, de 19 de junio, de las Cualificaciones y de la Formación Profesional. Madrid. Boletín Oficial del Estado (20 de junio 2002).

- (2003) Real Decreto 1506/2003, de 28 de noviembre, por el que se establecen las directrices de los certificados de profesionalidad. Madrid. Boletín Oficial del Estado (18 de diciembre de 2003).

- (2006) Ley Orgánica 2/2006 de Educación. Madrid. Boletín Oficial del Estado (4 de mayo de 2006).

- (2007) Ley Orgánica 4/2007, de 12 de abril, por la que se modifica la Ley Orgánica 6/2001, de 21 de diciembre, de Universidades. Madrid. Boletín Oficial del Estado (13 de abril de 2007).

BOPV (2004) Decreto 70/2004, de 27 de abril, por el que se regulan las pruebas para la obtención de los Títulos de Técnico y Técnico Superior de Formación Profesional Específica. Vitoria. Boletín Oficial del País Vasco (5 de mayo de 2004).

Boyatzis, R. (1982) The competent manager. New York, Wiley \& Sons.

Bunk, G. P. (1994) La transmisión de competencias en la formación y perfeccionamiento profesionales de la RFA. Revista de Formación Profesional, 1, 8-14. Berlín, CEDEFOP.

Colardyn, D. (2002) La evaluación basada en competencias. Documento conceptual. Web: www.ons.org/udse/secondary/documentos/1-Trad\%20ASSESSMENT20\%base-1.DOC (Consulta: 8-8-2007).

Comisión Europea (1996) Enseñar y aprender. Hacia la sociedad del conocimiento. Libro Blanco. Luxemburgo, Oficina de Publicaciones Oficiales de las Comunidades Europeas.

- (2000) Memorándum sobre el aprendizaje permanente. Bruselas, Comisión de las Comunidades Europeas.

- (2001a) Hacer realidad un espacio europeo del aprendizaje permanente. Bruselas, Comunicación de la Comisión.

- (2001b) Iniciativas nacionales para promover el aprendizaje a lo largo de la vida. CEDEFOP y EURIDICE. Madrid, Subdirección General de Información y Publicaciones del MEC.

- (2004) Principios para la identificación y validación de los aprendizajes no formales e informales. Brussel, Council of the European Union.

- (2006) Aprendizaje de adultos: Nunca es demasiado tarde para aprender. Bruselas, Comunicación de la Comisión Europea.

DeLors, J. y otros (1996) La educación encierra un tesoro. Madrid, Santillana-UNESCO. 
Dennery, M. (1997) Organiser le suivi de la formation. Methodes et outils, en SABÁn, 2000, op. cit. París, ESF Éditeurs.

DOGC (2002) Ley 17/2002, de 5 de julio de ordenación del Sistema de Ocupación y de creación del Servicio de Ocupación de Cataluña. Barcelona. Diario Oficial de la Generalitat de Catalunya (12 de julio de 2002).

- (2003) Decreto 176/2003, de 8 de julio, de creación del Instituto Catalán de las Cualificaciones Profesionales. Barcelona. Diario Oficial de la Generalitat de Catalunya (29 de julio de 2003).

EcheverRía, B. (2002) Gestión de la competencia de acción profesional. Revista de Investigación Educativa, vol. 20, n. ${ }^{\circ}$ 1, 7-43.

Gonczi, A. (1997) Problemas asociados con la implementación de la educación basada en la Competencia: de lo atomístico a lo holístico, en OIT. Formación basada en competencia laboral. Montevideo, CINTERFOR/OIT, 161-170.

GREFFE (1997) La mise en place de formations initiales en alternance: enjeux, problèmes et solutions. París, IIPE.

Grupo Técnico de Trabajo del Proyecto ERA (2004) El proyecto ERA y la validación de los aprendizajes no formales e informales. Diálogos. Educación y formación de personas adultas, n. ${ }^{\circ}$ 39-40, 65-73.

GutiérRez, A. M. y Castañeda, G. (2001) Propuesta teórica de evaluación de la educación basada en competencias. Rev. Enferm. IMSS 2001, 9 (3), 147-153. Web: http://www. imss.gob.mx/NR/rdonlyres/1B20C768-6D1C-463A-B270-E3F236705298/0/3_147153.pdf (Consulta: 5-6-2007).

Inchauspé, P. (1999) Vers une politique de la formation continue (Rapport final). Quebec, MELS, 85.

INCUAL (2003) Sistemas Nacionales de Cualificaciones y Formación Profesional. Madrid, Instituto Nacional de Empleo.

INE (2007) Encuesta de Población Activa. Ocupados por nivel de formación alcanzado. Instituto Nacional de Estadística. Web: http://www.ine.es/inebase2/datos.jsp (Consulta: 1-6-2007).

Jover, G.; Fernández, C. y Ruiz, M. (2005) El diseño de titulaciones y programas ante la convergencia europea, en Esteban Chapapría, V. (ed.) El espacio europeo de educación superior. Universidad Politécnica de Valencia.

MECD (2003) Proyecto experimental para la evaluación, reconocimiento y acreditación de las competencias profesionales (Proyecto ERA). Madrid, Ministerio de Educación, Cultura y Deportes.

Medina, Ó. (2007) El sistema de acreditación en la Formación Básica de Personas Adultas de Canarias. Las Palmas de Gran Canaria, Dirección General de Formación Profesional y Educación de Adultos de la Consejería de Educación, Cultura y Deportes del Gobierno de Canarias.

MeYer, N. y otros (1987) Expériences nord-americaines en reconnaissance des acquis (Québec-États Unis). Pratiques de Formation (Numéro Spécial), Avril 1987. Université de Paris VIII.

Monclús, A. (coord.) (2000) Formación y empleo: enseñanza y competencias. Granada, Comares.

- (2000) La formación de los trabajadores y el problema de las competencias en un contexto internacional, en Moncuús, A. (coord.) Formación y empleo: enseñanza y competencias. Granada, Comares, 3-26.

OCDE (2001) The role of National Qualifications Systems in promoting lifelong learning. Issues Paper Meeting of National Representatives and Experts. Comité de Educación. Paris 5-6 march. 
- (2002) Points-dès des debats et tendences nationales dans les systémes de qualifications. Résumés par pays. Paris 7-8 november.

- (2003) Más allá de la retórica: políticas y prácticas del aprendizaje de las personas adultas. París, OCDE.

OIT (1997) Formación basada en competencia laboral. Montevideo, CINTERFOR/OIT.

- (2002) Aprender y formarse para trabajar en la sociedad del conocimiento. Ginebra, Organización Internacional del Trabajo.

- (2004) Resolución 195, de junio de 2004 sobre la formación y el aprendizaje permanente. Ginebra, Organización Internacional del Trabajo.

Parlamento Europeo (2005) Directiva 2005/36/CE del Parlamento Europeo y del Consejo, de 7 de septiembre de 2005 relativa al reconocimiento de cualificaciones profesionales. Bruselas. Diario Oficial de la Unión Europea.

Perrenaud, Ph. (2002) Diez nuevas competencias para enseñar. Barcelona, Graó.

Rial, A. (2000) La formación para el trabajo: nuevos escenarios, nuevos requerimientos de competencias y cualificaciones, en MoncLús, A. (coord.) Formación y empleo: enseñanza y competencias. Granada, Comares, 233-256.

Rodríguez Moreno, M. L. (2006) Evaluación, balance y formación de competencias laborales transversales. Barcelona, Alertes.

Rodríguez Zambrano, H. (2007) El paradigma de las competencias hacia la educación superior. Revista de la Facultad de Ciencias Económicas, vol. XV, n. ${ }^{\circ}$ 1, 145-165. Web: http://www.umng.edu.co/revcieco/2007/julio.2007/VOLXV1/7.PARADIGMA.pdf (Consulta: 5-6-2007).

SABÁn, C. (2000) Dimensiones actuales de la formación y la función de las competencias, en Monclús, A. (coord.) Formación y empleo: enseñanza y competencias. Granada, Comares, 83-108.

Spencer, L. M y Spencer, S. M. (1993) Competence at work. New Cork, John Wiley and Sons.

UNESCO (1985) Cuarta Conferencia Internacional de Educación de Adultos. Informe final. París, UNESCO.

- (1997a) Declaración de Hamburgo sobre la Educación de Adultos. Quinta Conferencia Intergubernamental de Educación de Adultos (CONFITEA). Diálogos. Educación y formación de personas adultas, n. ${ }^{\circ} 11-12,7-10$.

- (1997b) Plan de acción para el futuro de la Educación de Adultos. Quinta Conferencia Intergubernamental de Educación de Adultos (CONFITEA). Diálogos. Educación y formación de personas adultas, n. ${ }^{\circ} 11-12,11-24$.

- (1997c) Recapitulación retrospectiva de los adelantos, las realizaciones y los problemas de la Educación de Adultos desde 1985, en Quinta Conferencia Intergubernamental de Educación de Adultos (CONFITEA). Documento de distribución limitada. Hamburgo.

Vergara, J. C. (2003) Las competencias: un paradigma por construir. Revista Escuela de Administración de Negocios, n. ${ }^{\circ} 48$ (mayo-agosto), 46-53.

VV.AA. (2001) Expérience et formation, Pratiques de Formation, Juin 2001. Université de Paris VIII. 